\title{
Optimization and Application of a Multiplex RT-PCR System for Simultaneous Detection of Five Potato Viruses Using 18S rRNA as an Internal Control
}

\author{
ZhiYou Du, College of Life Sciences, Zhejiang University, Hangzhou, 310029 P. R. China; JiShuang Chen, Col- \\ lege of Life Sciences, Zhejiang University, Hangzhou, 310029 P. R. China; Institute of Bioengineering, Zhejiang \\ Sci-Tech University, Hangzhou, 310018 P. R. China; and Chuji Hiruki, Department of Agricultural, Food and Nutri- \\ tional Science, University of Alberta, Edmonton, Alberta, T6G 2P5 Canada
}

\begin{abstract}
Du, Z., Chen, J., and Hiruki, C. 2006. Optimization and application of a multiplex RT-PCR system for simultaneous detection of five potato viruses using $18 \mathrm{~S}$ rRNA as an internal control. Plant Dis. 90:185-189.

Search for a host RNA molecule appropriate as an internal control for reverse transcriptionpolymerase chain reaction (RT-PCR) detection of viruses in potato (Solanum tuberosum) was conducted. The $18 \mathrm{~S}$ ribosomal RNA (rRNA) was compared with the commonly used nad2 mRNA in terms of detection sensitivity and degradation kinetics. Detection of $18 \mathrm{~S}$ rRNA was 5 magnitudes more sensitive than that of nad 2 mRNA. The $18 \mathrm{~S}$ rRNA also displayed degradation kinetics more similar to that of Potato virus $X$ (PVX). Based on this result, reaction components and cycling parameters were optimized for a multiplex RT-PCR protocol for simultaneous detection of five potato viruses using $18 \mathrm{~S}$ rRNA as an internal control. The protocol simultaneously amplified cDNAs from Potato virus A, PVX, Potato virus $Y$, Potato leaf roll virus, Potato virus $S$, and 18S rRNA. The multiplex RT-PCR protocol was able to detect all viruses in different combinations. The technique was 100-fold greater for detection of PVX than that of commercial double-antibody sandwich-enzyme-linked immunosorbent assay (DAS-ELISA), and also could detect viruses in some samples that DAS-ELISA failed to detect. This multiplex RT-PCR technique demonstrates a higher sensitivity of virus detection than DAS-ELISA.
\end{abstract}

Additional keywords: NADH hydrogenase subunit II, tissue degradation

More than 25 viruses have been reported to infect potato (Solanum tuberosum) (15). Potato virus $Y$ (PVY), Potato virus $X$ (PVX), Potato virus A (PVA), Potato virus $S$ (PVS), and Potato leaf roll virus (PLRV) are known to cause serious diseases, and significantly reduce the yield and quality of potato crops. These viruses cause remarkable economic losses in potato production in China and North America $(14,17,20,22)$. Accurate and timely diagnosis of the viruses is the first requirement for their control.

Techniques used for the diagnosis of potato viruses include biological assay, electron microscopy, serology, virus-specific double-stranded RNA analysis, nucleic acid hybridization, and polymerase chain reaction (PCR)-based methods. Due to their rapidity and simplicity, molecular techniques (e.g., reverse transcription

Corresponding author: JiShuang Chen

E-mail: chenjs@zist.edu.cn

Current address of JiShuang Chen: Kaixuan Road 268\#, College of Life Sciences, Zhejiang University, Hangzhou 310029 Zhejiang, P. R. China.

Accepted for publication 6 September 2005.

DOI: 10.1094/PD-90-0185

(C) 2006 The American Phytopathological Society
(RT)-PCR, real-time PCR, nucleic acid hybridization) and serological techniques (e.g., double-antibody sandwich-enzymelinked immunosorbent assay [DASELISA]) are popular in diagnostic laboratories. However, most of the above techniques are designed for specific detection of a single virus. Recently, the potential of microarray technology for plant viral diagnosis has been investigated using a range of potato viruses as a model system (4). The microarray technique can detect multiple targets in a single assay, but high cost and the requirement for specific instruments limit its usefulness as a routine diagnostic tool for plant viruses.

Multiplex RT-PCR accommodates several primer pairs in one reaction, saving time and expense, especially when large numbers of samples need to be tested. Since the first multiplex PCR system was developed for the detection of mutations in the dystrophin gene (5), this technique has been applied to the detection of plant viruses for several years $(2,8,11-13,19)$. Two multiplex RT-PCR formats have been described for the diagnosis of multiple potato viruses $(11,12)$. In the first format, oligo(dT) was used as a common primer for the synthesis of first-strand cDNA from viral RNA (11). This format effectively detected multiple potato viruses in tubers, but interference from plant mRNA made it unsuitable for the detection of the same viruses in leaves. In the second format, random primers were used for first-strand cDNA or a cDNA pool (12). This format detected several viruses from aphids, leaves, and tubers (12). Both formats were developed through detecting viral RNA extracted from purified viral particles. To rule out false negative results due to factors such as the presence of PCR inhibitors, some reports used a plant NADH dehydrogenase mRNA as an internal control for the success of RNA extraction and RT-PCR reaction $(1,10,19)$. Although the choice to use an internal control depends on a researcher's preference, it can facilitate troubleshooting of problems encountered during detection assays.

In this study, we compared the sensitivities and stabilities of $18 \mathrm{~S}$ rRNA and nad2 mRNA as internal controls, and then selected 18S rRNA as the internal control in a multiplex RT-PCR system optimized for simultaneous detection of five potato viruses from infected potato leaf tissues.

\section{MATERIALS AND METHODS}

Viral isolates and potato plants. Previously identified strains of PVY, PVX, PVA, PVS, and PLRV were kindly provided by General Administration of Quality Supervision, Inspection and Quarantine of the People's Republic of China, Beijing, and maintained in a greenhouse at $28^{\circ} \mathrm{C}$ with a $13-\mathrm{h}$ photoperiod. PVS and PLRV were maintained on Nicotiana tabacum and Datura stramonium, respectively, while PVX, PVY, and PVA were singly maintained on $N$. glutinosa. Four potato cultivars, 'Atlantic', 'Calwhite', 'Frontier Russet', and 'Shepody', were kindly supplied by the International Potato Center (CIP), Shandong, China, and planted in a field plot at the Hangzhou Institute of Vegetable Science and Technology, Zhejiang, China. PVX virions were extracted from $200 \mathrm{~g}$ of PVXinfected tobacco leaf tissues using a procedure described by Zhou et al. (23), and quantified with a spectrophotometer (SpectraMax Plus $^{384}$, Molecular Devices Co., Sunnyvale, CA).

Nucleic acid extraction. Leaf tissue $(0.1 \mathrm{~g})$ was frozen in liquid nitrogen and ground in a mortar to a fine powder. $\mathrm{Nu}$ cleic acid was isolated from the powdered tissue using the RNeasy Plant Mini Kit 
(Qiagen Ltd., Crawley, UK) or TRIzol reagent (Invitrogen, Carlsbad, CA) according to manufacturer's instructions.

Comparison of $18 \mathrm{~S}$ rRNA and $n a d 2$ mRNA as internal controls. Sequences of 18S rRNA from $S$. tuberosum (X67238), N. tabacum (AJ236016), and Lycopersicon esculentum (X51576) were used to design 18S rRNA-specific primers 18SF/18SR (Table 1). Sequence of the NADH dehydrogenase subunit II (nad2 gene) from $S$. tuberosum (X93575) was used to design the PotatoNad2 primers (Table 1). The nad 2 gene contains three exons, a, b, and c, separated by two introns. The forward primer (PotatoNad2F) crosses the splice junction of exons a and b. The last two 3' nucleotides of this primer are homologous to the first two nucleotides of exon $b$. The reverse primer (PotatoNad2R) is located entirely within exon $b$. To compare the sensitivities of $18 \mathrm{~S}$ rRNA and nad 2 mRNA as internal controls, total RNA was extracted from potato leaf tissue as described above and digested with DNase I (TaKaRa Biotechnology [Dalian] Co., Ltd., China) according to the manufacturer's instructions. The RNA extract was diluted in a tenfold series with RNA extract from $E s$ cherichia coli strain DH5 $\alpha$. First strand cDNA was synthesized from these dilution samples using a 9-mer random primer and then amplified separately with primer pairs 18SF/18SR and PotatoNad2F/ PotatoNad2R (Table 1). To investigate the effect of tissue degradation on 18S rRNA and $\operatorname{nad} 2$ mRNA, fresh leaves of potato infected with PVX were divided into 12 equal sections by weight and wrapped in plastic bags. Six sections of these tissues were placed at room temperature, while the other six were placed at $4^{\circ} \mathrm{C}$. At day 0 , $2,4,6,8$, and 10 , one section from each incubation temperature was transferred into a freezer maintained at $-70^{\circ} \mathrm{C}$. At the end of the final incubation, total RNA was extracted from all sectioned samples and digested with DNase I (TaKaRa Biotechnology [Dalian]) according to the manufacturer's instructions. The quality of all
RNA samples was examined by agaroseformaldehyde electrophoresis. First-strand cDNA was synthesized from these RNA samples with a 9-mer random primer and amplified with primer pairs PVXF/PVXR (Table 1), 18SF/18SR, and PotatoNad2F/ PotatoNad2R separately under the conditions described below.

Single virus RT-PCR. On the basis of conserved regions of coat proteins, the forward and reverse primers for specific viruses were designed by using the software of Primer Premier 5.0 (Premier Biosoft International, Palo Alto, CA) (Table 1). First-strand cDNA was synthesized from viral RNA with a virus-specific reverse primer in $20-\mu \mathrm{l}$ reactions using AMV reverse transcriptase (TaKaRa Biotechnology [Dalian]) according to the manufacturer's instructions. PCR was performed in a thermocycler (Biometra, Germany) using Taq Hot Start (HS) DNA polymerase (TaKaRa Biotechnology [Dalian]) according to the manufacturer's instructions. A $25-\mu$ l PCR reaction mixture consisted of $18.25 \mu \mathrm{l}$ double-distilled water, $2.5 \mu \mathrm{l}$ of $10 \times$ PCR buffer (100 mM Tris-HCl, pH 8.3, 500 $\mathrm{mM} \mathrm{KCl}, 15 \mathrm{mM} \mathrm{MgCl} 2$ ), $2 \mu \mathrm{l}$ dNTPs (2.5 $\mathrm{mM}$ each), $1 \mu \mathrm{l}$ forward and reverse primer (5 $\mu \mathrm{M}$ each), $0.25 \mu \mathrm{l} \mathrm{Taq}$ HS (5 U/ $\mu \mathrm{l})$, and $2 \mu \mathrm{l}$ RT product. PCR reaction was conducted with one cycle of $94^{\circ} \mathrm{C}$ for $3 \mathrm{~min}$ followed by 35 cycles of $94^{\circ} \mathrm{C}$ for $30 \mathrm{~s}$, $58^{\circ} \mathrm{C}$ for $30 \mathrm{~s}, 72^{\circ} \mathrm{C}$ for $25 \mathrm{~s}$, and an additional cycle of $72^{\circ} \mathrm{C}$ for $5 \mathrm{~min}$. The PCR products were visualized by electrophoresis in $3.5 \%$ agarose gels stained with ethidium bromide. All target DNA fragments of the five viruses, 18S rRNA, and nad 2 mRNA were subsequently cloned and sequenced.

Optimization of multiplex RT-PCR. A mixture of the five viruses was prepared by mixing equal weights of leaf tissues individually infected with each virus. Viral RNA was extracted from the mixture as described above. Protocol for the multiplex RT reaction was identical to the single virus assays described above except that the reaction mixture included virus- specific reverse primers $(0.5 \mu \mathrm{M}$ each $)$ for the five viruses and the $18 \mathrm{~S}$ rRNA reverse primer $(0.1 \mu \mathrm{M})$. The RT product was amplified separately by PCR with $18 \mathrm{~S}$ rRNA and each virus-specific primer pair of the five viruses to ensure that the RT product contained first-strand cDNA from all five viruses and 18S rRNA. Subsequently, multiplex PCR was carried out with six primer pairs, PVAF/PVAR, PVXF/PVXR, PVYF/PVYR, PVSF/ PVSR, PLRVF/PLRVR, and 18SF/18SR in a single reaction (Table 1). Multiplex PCR reactions were optimized by a series of assays by variation of DNA polymerase, dNTPs, $\mathrm{MgCl}_{2}$, and primer concentrations, as well as variations of annealing temperature, extension time, and cycling numbers.

DAS-ELISA. DAS-ELISA was performed in 96-well microtiter plates using commercial reagents according to the instructions of the manufacturer (Advanced Diagnostics International, LLC, USA). The test results were measured at $405 \mathrm{~nm}$ with a spectrophotometer (SpectraMax Plus $^{384}$, Molecular Devices). A sample was regarded as positive if its absorbance value exceeded the mean value of the healthy controls by 3 standard deviations.

Sensitivities of multiplex RT-PCR and DAS-ELISA. To compare the sensitivity of the multiplex RT-PCR with that of DAS-ELISA, tenfold serial dilutions of PVX samples were prepared by diluting 50 $\mu \mathrm{g}$ purified PVX virions with healthy potato leaf sap. For multiplex RT-PCR, healthy potato leaf sap was prepared by grinding healthy potato leaf tissue with TRIzol reagent (Invitrogen). For DASELISA, leaf sap was prepared by grinding healthy potato leaf tissue with SB1 buffer (1× phosphate-buffered saline, $\mathrm{pH} 7.4$, containing $0.2 \%$ powdered egg albumin [wt/vol], $1 \%$ polyvinylpyrrolidone [wt/vol], $0.13 \%$ sodium sulfite [wt/vol], $0.02 \%$ sodium azide [wt/vol], and $1 \%$ Tween 20 [wt/vol]). The RNA extraction, multiplex RT-PCR, and DAS-ELISA were performed as described above.

Table 1. List of reverse transcription-polymerase chain reaction (RT-PCR) primers for viruses, $18 \mathrm{~S}$ rRNA, and nad2 mRNA

\begin{tabular}{|c|c|c|c|c|}
\hline Virus $^{\mathrm{a}}$ & Code no. & Primer sequence $\left(5^{\prime}-3^{\prime}\right)^{b}$ & Position (accession no.) & Product size (bp) \\
\hline \multirow[t]{2}{*}{ PVA } & PVAF & TTTCTATGAGATCACTGCAACCACT & 9140-9164 (Z21670) & 116 \\
\hline & PVAR & TGACATTTCCGTCCAGTCCAA & 9235-9255 (Z21670) & \\
\hline \multirow{2}{*}{ PVX } & PVXF & AACTGGCAAGCACAAGGTTTCA & 6088-6109 (D00344) & 145 \\
\hline & PVXR & CAGTTTGGGCAGCATTCATTTC & 6211-6232 (D00344) & \\
\hline \multirow[t]{2}{*}{ PVY } & PVYF & ATACTCGRGCAACTCAATCACA & 8817-8838 (D00441) & 166 \\
\hline & PVYR & CСАТССАТСАТААСССАААСТС & $8961-8982$ (D00441) & \\
\hline \multirow[t]{2}{*}{ PLRV } & PLRVF & CСАCТCCAACTCCCCAGAAG & 4363-4382 (D00530) & 208 \\
\hline & PLRVR & TACATAGGGACGGCTTGCAT & $4551-4570(\mathrm{D} 00530)$ & \\
\hline \multirow[t]{2}{*}{ PVS } & PVSF & ACCRGATCCGACAAGCTCAGG & 2309-2329 (Y15625) & 342 \\
\hline & PVSR & GCCATTTGCTCRGTGTTCG & $2632-2650(\mathrm{Y} 15625)$ & \\
\hline \multirow{2}{*}{$18 \mathrm{~S}$ rRNA ${ }^{\mathrm{c}}$} & $18 \mathrm{SF}$ & GAGAAACGGCTACCACATCCA & $399-419($ X67238) & 255 \\
\hline & $18 \mathrm{SR}$ & CGTGCCATCCCAAAGTCCAAC & 633-653 (X67238) & \\
\hline \multirow[t]{2}{*}{$\operatorname{nad} 2$ gene $^{\mathrm{c}}$} & PotatoNad2F & CAAGATCACTGCAGTTCCTTTTCAT & $5775-5797,8266,8277(X 93575)$ & 292 \\
\hline & PotatoNad2R & TCCACATGAGAAACCAGTACGAATA & 8513-8537 (X93575) & \\
\hline
\end{tabular}

\footnotetext{
a $\mathrm{PVA}=$ Potato virus $A ; \mathrm{PVX}=$ Potato virus $X ; \mathrm{PVY}=$ Potato virus $Y ; \mathrm{PLRV}=$ Potato leaf roll virus $; \mathrm{PVS}=$ Potato virus $S$.

b R: A or G.
}

${ }^{\mathrm{c}}$ Internal control. 


\section{RESULTS}

Comparison of $18 S$ rRNA and $n a d 2$ mRNA as internal controls. Sensitivity of 18S rRNA internal control was compared with that of nad2 mRNA internal control by detecting $18 \mathrm{~S}$ rRNA and nad 2 mRNA, respectively, with RT-PCR in serial dilutions of potato RNA extract. The $18 \mathrm{~S}$ rRNA was detected up to a $10^{9}$ dilution, $10^{5}$ times greater than nad 2 mRNA (Fig. 1). No amplicons were produced from the potato RNA extract through direct PCR amplification (Fig. 1A, lane 1, and Fig. 1B, lane 1), and no amplicons were produced from the E. coli RNA extract through RTPCR amplification (Fig. 1A, lane 2, and Fig. 1B, lane 2). Stabilities of 18S rRNA, nad2 mRNA, and PVX were analyzed with the potato leaves incubated at $4^{\circ} \mathrm{C}$ and room temperature for different periods. Results showed that $18 \mathrm{~S}$ rRNA, nad2 mRNA, and PVX were detected in tissues incubated at $4^{\circ} \mathrm{C}$ at all six time points (Fig. $2 \mathrm{~B}, \mathrm{D}$, and $\mathrm{F}$ ), but the concentration of the product from nad2 mRNA decreased sharply as estimated by decreasing stain intensity after incubation for 10 days (Fig. 2D, lane 6). 18S rRNA and PVX were also detected in tissues incubated at room temperature at each time point (Fig. 2A and E); however, nad2 mRNA was not detectable after incubation for more than 8 days (Fig. 2C, lanes 5 and 6). Agaroseformaldehyde electrophoresis showed that

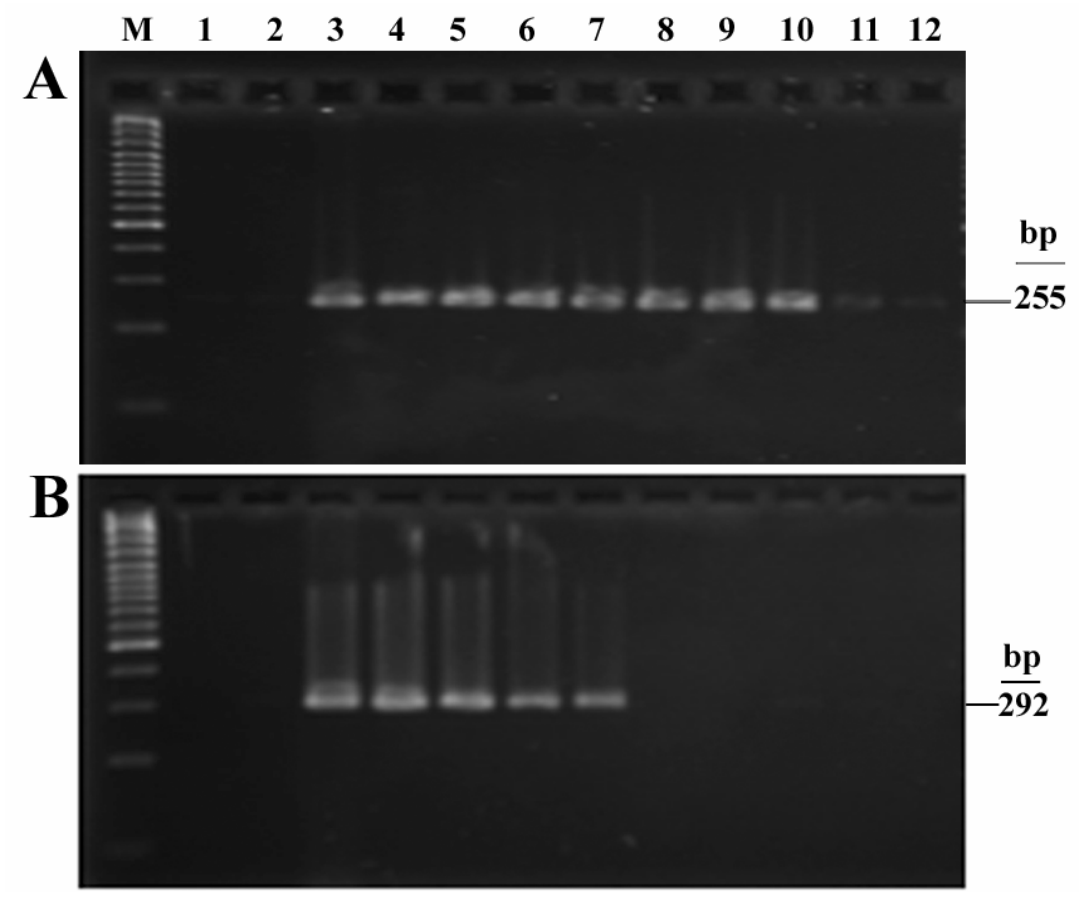

Fig. 1. Detection of $18 \mathrm{~S}$ rRNA and nad2 mRNA by reverse transcription-polymerase chain reaction (RT-PCR) with primer pairs 18SF/18SR (A) and PotatoNad2F/PotatoNad2R (B). Lane M, DNA marker; lane 1, RNA from potato leaf tissue without reverse transcription; lane 2, Escherichia coli strain DH5 $\alpha$ RNA; lanes 3 to 12 , amplification products of potato RNA diluted, $10^{0}, 10^{1}, 10^{2}, 10^{3}, 10^{4}$, $10^{5}, 10^{6}, 10^{7}, 10^{8}$, and $10^{9}$, respectively.

RNA samples from tissues stored at room temperature, especially for more than 8 days, displayed a higher level of RNA degradation than those from tissues stored at $4^{\circ} \mathrm{C}$ (data not shown). Since $18 \mathrm{~S}$ rRNA displayed much higher detection sensitivity than nad2 mRNA and similar degradation kinetics in leaf tissues to PVX RNA, we believe it is a better internal control for virus detection from tissue samples. Therefore, 18S rRNA was selected as the internal control to optimize the multiplex RTPCR system for detecting five potato viruses.

Single virus RT-PCR. To determine an optimal annealing temperature among the primer pairs, PCR amplification was conducted at $52^{\circ} \mathrm{C}, 53.5^{\circ} \mathrm{C}, 55.5^{\circ} \mathrm{C}, 57.4^{\circ} \mathrm{C}$, and $60.0^{\circ} \mathrm{C}$. Only one target band was produced for each virus when using the primer pairs PVAF/PVAR, PVXF/PVXR, and PVYF/PVYR at all annealing temperatures. Nonspecific bands were observed when using the primer pairs PLRVF/PLRVR, PVSF/PVSR, and 18SF/ $18 \mathrm{SR}$ at $52^{\circ} \mathrm{C}, 53.5^{\circ} \mathrm{C}$, and $55.5^{\circ} \mathrm{C}$, but not at $57.4^{\circ} \mathrm{C}$ and $60.0^{\circ} \mathrm{C}$ (data not shown). Hence, $58^{\circ} \mathrm{C}$ was used as the optimum annealing temperature in assays using multiplex RT-PCR.

Multiplex RT-PCR. The RT product synthesized from the mixture of the five viruses was amplified separately by PCR with $18 \mathrm{~S}$ rRNA and each virus-specific primer pair of the five viruses. As predicted, amplicons of the expected size for PVA (116 bp), PVX (145 bp), PVY (166 bp), PLRV (208 bp), PVS (342 bp), and 18S rRNA (255 bp) were all detected (Fig. 3 ). Thus, the RT product contained firststrand cDNA from all five viruses and 18S rRNA.

Next, the RT product was used as a DNA template for the subsequent optimization assays of multiplex PCR. Major reaction components for multiplex $\mathrm{PCR}$, including DNA polymerase, $\mathrm{MgCl}_{2}$, dNTPs, and primer concentrations were systematically optimized. Optimal results

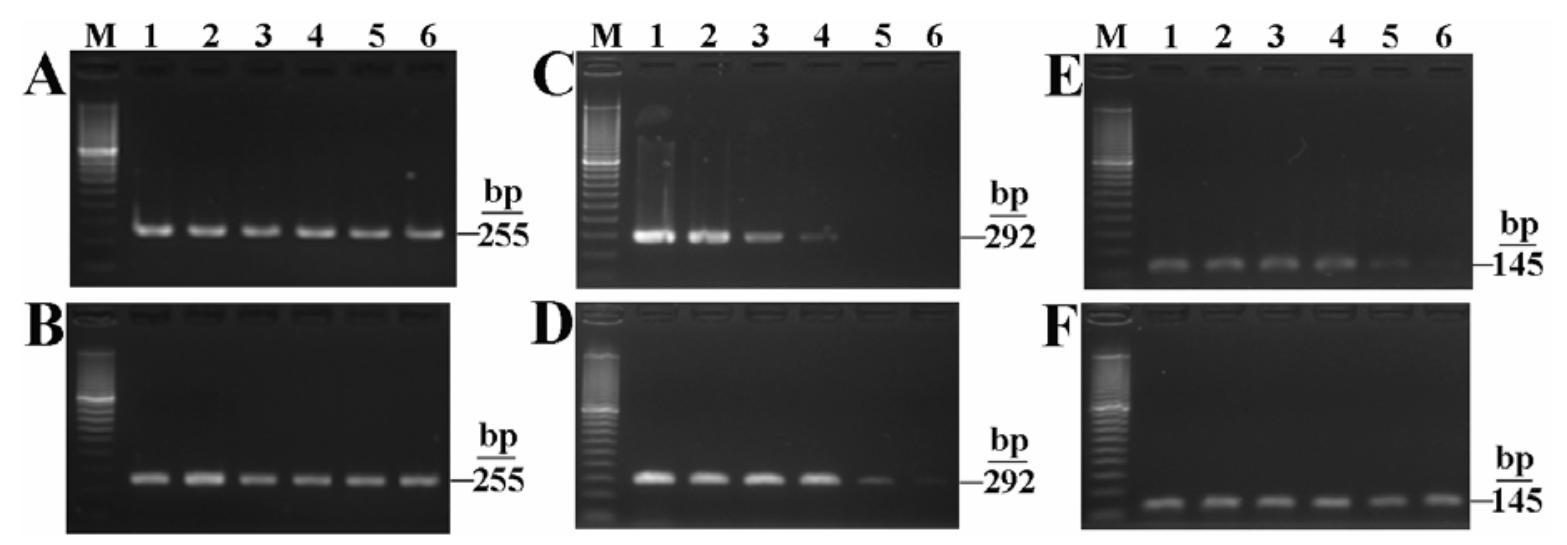

Fig. 2. Detection of $18 \mathrm{~S}$ rRNA, nad2 mRNA, and Potato virus $X$ (PVX) by reverse transcription-polymerase chain reaction (RT-PCR) with primer pairs 18SF/18SR (A and B), PotatoNad2F/PotatoNad2R (C and D), and PVXF/PVXR (E and F). A, C, and E, potato leaves incubated at room temperature; B, D, and F, potato leaves incubated at $4^{\circ} \mathrm{C}$. Lane M, 100-bp DNA ladder; lanes 1 to 6 , potato leaf tissue samples incubated for $0,2,4,6,8$, and 10 days, respectively. 
were achieved when the reaction mixture consisted of $0.1 \mathrm{U} / \mu \mathrm{T} \mathrm{Taq}$ HS DNA polymerase and $4.0 \mathrm{mM} \mathrm{MgCl}_{2}$ (data not shown). Optimum thermocycling results were achieved using 35 cycles of $94^{\circ} \mathrm{C}$ for $30 \mathrm{~s}, 58^{\circ} \mathrm{C}$ for $30 \mathrm{~s}$, and $72^{\circ} \mathrm{C}$ for $25 \mathrm{~s}$. Virus mixtures containing zero, one, two, three, four, or five different viruses were analyzed by this optimized protocol. Amplicons of the expected size were successfully produced in all tested virus mixtures (Fig. 4).

Sensitivities of optimized multiplex RT-PCR and DAS-ELISA. Sensitivities of the optimized multiplex RT-PCR and DAS-ELISA were compared by detecting PVX in serial concentrations of PVX virions, which were diluted with healthy leaf sap. The multiplex RT-PCR protocol de-

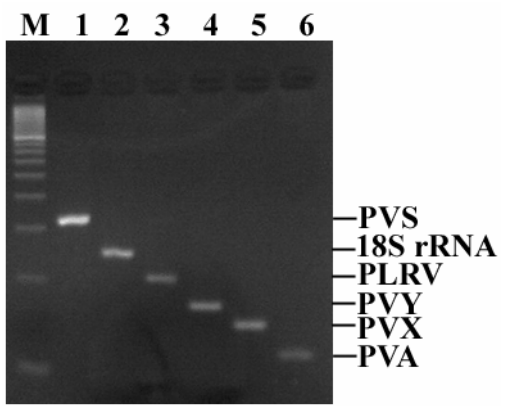

Fig. 3. Detection of five viruses and $18 \mathrm{~S}$ rRNA from a mixture of individually infected leaf tissues by reverse transcription-polymerase chain reaction (RT-PCR) using virus-specific primer pairs. Lane M, 100-bp DNA ladder; lane 1, PVSF/PVSR; lane 2, 18SF/18SR; lane 3, PLRVF/PLRVR; lane 4, PVYF/PVYR; lane 5, PVXF/PVXR; lane 6, PVAF/PVAR. Amplification products corresponding to individual viruses and the 18S rRNA are indicated on the right.

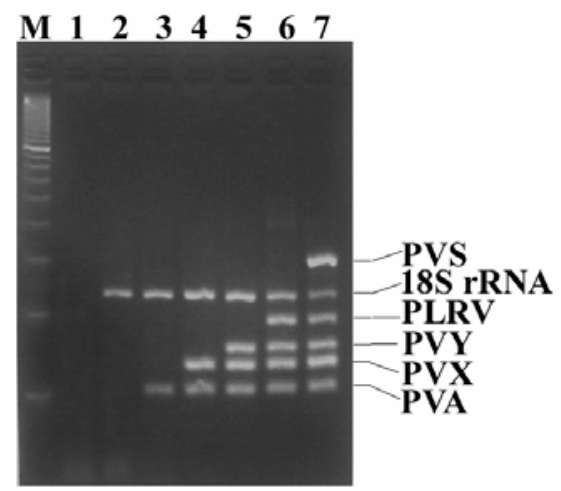

Fig. 4. Detection of different virus combinations by multiplex reverse transcription-polymerase chain reaction (RT-PCR). Lane M, 100-bp DNA ladder; lane 1, water control; lane 2, 18S rRNA; lane 3, 18S rRNA and Potato virus A (PVA); lane 4, 18S rRNA, PVA, and Potato virus $X$ (PVX); lane 5, 18S rRNA, PVA, PVX, and Potato virus $Y$ (PVY); lane 6, 18S rRNA, PVA, PVX, PVY, and Potato leaf roll virus (PLRV); lane 7, 18S rRNA, PVA, PVX, PVY, PLRV, and Potato virus $S$ (PVS). Amplification products corresponding to individual viruses and the $18 \mathrm{~S}$ rRNA are indicated on the right. tected as little as $0.5 \mathrm{pg}$ of PVX without any nonspecific amplicons (Fig. 5A). The sensitivity of this protocol is 100 times higher than that of DAS-ELISA (Fig. 5B).

Use of multiplex RT-PCR and DASELISA to analyze field samples. We analyzed 20 field potato samples by multiplex RT-PCR and DAS-ELISA. DAS-ELISA detected PVY in one sample and PVS in 13 samples. PVA, PVX, and PLRV were not detected in any sample with DASELISA. Multiplex RT-PCR confirmed the presence of PVY and PVS in samples detected by DAS-ELISA. However, multiplex RT-PCR was able to detect PVX in one sample and PVS in another sample that was not detected by DAS-ELISA. The two samples were confirmed to be infected with PVX and PVS, respectively, by single virus RT-PCR (data not shown).

\section{DISCUSSION}

A host RNA molecule used as an internal control in a virus-detection system should have similar degradation kinetics to viral RNA in host tissues. Smith et al. (18) found that rRNA from mouse brain tissues had similar degradation properties to viral RNA and was more suitable as an internal control than actin mRNA. Plant NADH dehydrogenase mRNA has been used regularly as an internal control in virus-
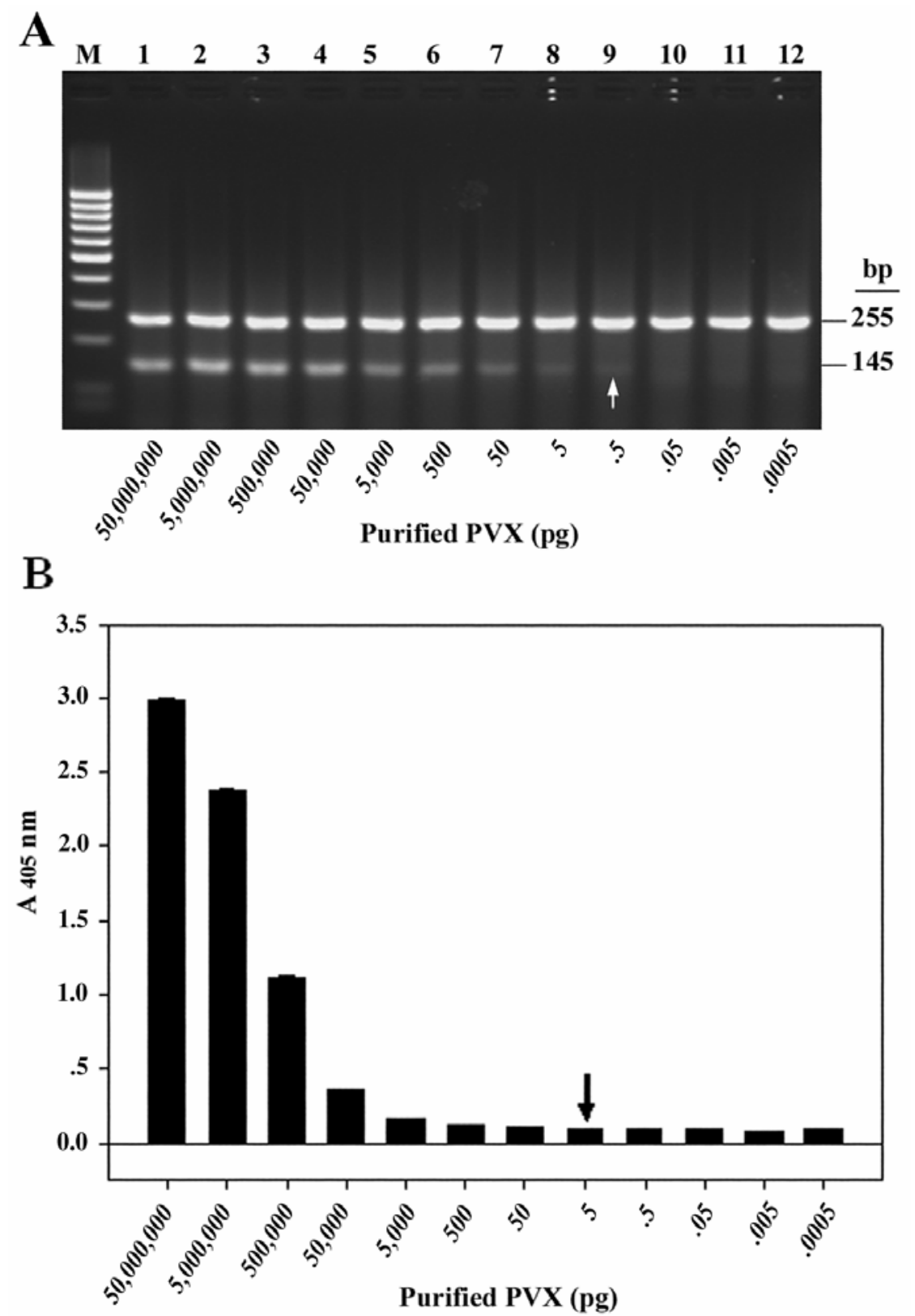

Fig. 5. Sensitivities of multiplex reverse transcription-polymerase chain reaction (RT-PCR) and double-antibody sandwich-enzyme-linked immunosorbent assay (DAS-ELISA) for Potato virus $X$ (PVX) detection in serial dilutions of PVX virions. A, Multiplex RT-PCR; B, DAS-ELISA. In both assays, tenfold serial dilutions of PVX virions were prepared by diluting $50 \mu \mathrm{g}$ purified PVX virions with healthy potato leaf sap. Average absorbance value $\left(A_{405 \mathrm{~nm}}\right)$ and standard error are presented in Panel B. The detection limits of both methods are indicated with arrowheads. 
detection systems $(1,10,19)$. By comparing $18 \mathrm{~S}$ rRNA with nad 2 mRNA from potato leaf tissues, it was shown that amplification of $18 \mathrm{~S}$ rRNA was $10^{5}$ times greater in sensitivity than that of $n a d 2$ mRNA (Fig. 1). In addition, both $18 \mathrm{~S}$ rRNA and PVX were amplified from tissue samples incubated at $4{ }^{\circ} \mathrm{C}$ and room temperature for up to 10 days, but nad 2 mRNA was not detectable from the samples incubated at room temperature for more than 8 days (Fig. 2), indicating the degradation kinetics of $18 \mathrm{~S}$ RNA was more similar to PVX RNA than that of nad2 mRNA. Therefore, as an internal control for potato virus detection, 18S rRNA was better than nad2 mRNA in terms of detection sensitivity and degradation kinetics.

By locating one of the mRNA-specific primers over the splice junction of exons a and $b$, the primers were shown to be specific for the mRNA amplification even in the presence of the genomic DNA $(10,19)$. However, because rDNA does not have introns, it is not possible to design primers for rRNA that will not amplify rDNA. Therefore, preventing contamination of RNA preparation with plant genomic DNA becomes an important issue if 18S rRNA is used as an internal control. The RNA extraction kits used in this study efficiently removed plant genomic DNA, making it possible for us to use 18S rRNA as an internal control in the multiplex RT-PCR.

Compared with several individual RTPCR reactions, multiplex RT-PCR is more convenient and less expensive. This method has been successfully applied to viral diagnostics $(2,6,8,11-13,19)$. Either random primers $(12,19)$ or virus-specific primers $(6,8,9)$ have been used for the synthesis of first-strand cDNA in multiplex RT-PCR protocols. In this study, virusspecific reverse primers were used for RT reactions. Critical factors affecting a multiplex PCR system were investigated. One of the principal challenges in developing a multiplex RT-PCR system is overcoming the formation of primer dimers (21). Some hot start PCR methods, including the method utilizing AmpliTaq Gold (Applied Biosystems, Foster City, CA), have been demonstrated to minimize dimer formation (3). Hence, Taq Hot Start DNA polymerase was used in our multiplex RT-PCR system. Primer design is also a critical factor for reduction of secondary structures formed between primers. Another consideration in primer design is the resulting amplicon size. Several studies have shown that short DNA fragments were amplified more efficiently than longer fragments $(12,16)$. The size range between the smallest and largest products should not exceed $300 \mathrm{bp}$ (21). In this study, primers were designed to amplify six target DNA fragments ranging from 106 to $341 \mathrm{bp}$. Results from a series of optimization assays showed that several parameters, including the concentration of $T a q$ HS DNA polymerase and $\mathrm{MgCl}_{2}$, annealing temperature, extension time, and cycle numbers, were critical for optimal results with multiplex RT-PCR.

Failure to optimize the multiplex RTPCR system may result in poor sensitivity (7). The sensitivity of our optimized system was compared with that of commercial DAS-ELISA in detecting PVX virions. The former detected as little as $0.5 \mathrm{pg}$ of PVX virions, 100 times greater in sensitivity than the latter (Fig. 5). The fact that multiplex RT-PCR detected PVX and PVS in field potato samples where DAS-ELISA failed to detect them, also demonstrated that this new system has greater sensitivity. In conclusion, the optimized multiplex RTPCR combined with the 18S rRNA internal control is a convenient and sensitive protocol for simultaneous detection of the five economically important potato viruses.

\section{ACKNOWLEDGMENTS}

This work was supported by the National High Technology Research and Development Program of China (863 Program, 2002AA241121). We thank Mingfu Li, in General Administration of Quality Supervision, Inspection and Quarantine of the People's Republic of China, Beijing, China, for his kind provision of potato viruses for this study.

\section{LITERATURE CITED}

1. Bariana, H. S., Shannon, A. L., Chu, P. W. G., and Waterhouse, P. M. 1994. Detection of five seedborne legume viruses in one sensitive multiplex polymerase chain reaction test. Phytopathology 84:1201-1205.

2. Bertolini, E., Olmos, A., Martinez, M. C., Gorris, M. T., and Cambra, M. 2001. Singlestep multiplex RT-PCR for simultaneous and colourimetric detection of six RNA viruses in olive trees. J. Virol. Methods 96:33-41.

3. Birch, D. E., Kolmondin, L., Laird, W. J., McKinney, N., Wong, J., Young, K. K. Y., Zangenberg, G. A., and Zoccoli, M. A. 1996. Amplified hot start PCR. Nature 381:445-446.

4. Boonham, N., Walsh, K., Smith, P., Madagan, K., Graham, I., and Barker, I. 2003. Detection of potato viruses using microarray technology: Towards a generic method for plant viral disease diagnosis. J. Virol. Methods 108:181-187.

5. Chamberlain, J. S., Gibbs, R. A., Ranier, J. E., Nguyen, P. N., and Caskey, C. T. 1988. Deletion screening of the Duchenne muscular dystrophy locus via multiplex DNA amplification. Nucleic Acid Res. 16:11141-11156.

6. Corne, J. M., Green, S., Sanderson, G., Caul, E. O., and Johnston, S. L. 1999. A multiplex RT-PCR for the detection of parainfluenza viruses 1-3 in clinical samples. J. Virol. Methods 82:9-18.

7. Elnifro, E. M., Ashshi, A. M., Cooper, R. J., and Klapper, P. E. 2002. Multiplex PCR: Optimization and Application in Diagnostic Vi- rology. Clin. Microbiol. Rev. 13(4):559-570.

8. Hauser, S., Weber, C., Vetter, G., Stevens, M., Bwuve, M., and Lemaire, O. 2000. Improved detection and differentiation of poleroviruses infecting beet or rape by multiplex RT-PCR. J. Virol. Methods 89:11-21.

9. Jacobi, V., Bachand, G. D., Hamelin, R. C. and Castello, J. D. 1998. Development of a multiplex immunocapture RT-PCR assay for detection and differentiation of tomato and tobacco mosaic tobamoviruses. J. Virol. Methods 74:167-178.

10. Menzel, W., Jelkmann, W., and Maiss, E. 2002. Detection of four apple viruses by multiplex RT-PCR assays with coamplification of plant mRNA as internal control. J. Virol. Methods 99:81-92.

11. Nie, X., and Singh, R. P. 2000. Detection of multiple potato viruses using an oligo(dT) as a common cDNA primer in multiplex RT-PCR. J. Virol. Methods 86:179-185.

12. Nie, X., and Singh, R. P. 2001. A novel usage of random primers for multiplex RT-PCR detection of virus and viroid in aphids, leaves, and tubers. J. Virol. Methods 91:37-49.

13. Nie, X., and Singh, R. P. 2002. A new approach for the simultaneous differentiation of biological and geographical strains of potato virus $\mathrm{Y}$ by uniplex and multiplex RT-PCR. J. Virol. Methods 104:41-54.

14. Pang, W. F., and Wang, X. Y. 1997. Primary study on identification of potato virus in Hebei province, China. J. Hebei Agric. Sci. 1:19-23. (In Chinese)

15. Salazar, L. F., ed. 1996. Potato viruses and their control. Centro Internacional de la Papa, Peru.

16. Singh, M., and Singh, R. P. 1997. Potato virus Y detection: Sensitivity of RT-PCR depends on the size of fragment amplified. Can. J. Plant Pathol. 19:149-155.

17. Singh, R. P. 1999. Development of the molecular methods for potato virus and viroid detection and prevention. Genome 42:592-604.

18. Smith, J., McElhinney, L. M., Heaton, P. R., Black, E. M., and Lowings, J. P. 2000. Assessment of template quality by the incorporation of an internal control into a RT-PCR for the detection of rabies and rabies-related viruses. J. Virol. Methods 84:107-115.

19. Thompson, J. R., Wetzel, S., Klerks, M. M., Vašková, D., Schoen, C. D., Špak, J., and Jelkmann, W. 2003. Multiplex RT-PCR detection of four aphid-borne strawberry viruses in Fragaria spp. in combination with a plant mRNA specific internal control. J. Virol. Methods 11:85-93.

20. Wang, X. F., Liu, S. B., Wang, Y. F., Liu, W., and Jiang, L. 2002. Primary report on species and distribution of potato viruses in Dalian province, China. Liaoning Agric. Sci. 5:41-41. (In Chinese)

21. Zangenberg, G., Saiki, R. K., and Reynolds, R. 1999. Multiplex PCR: Optimization Guidelines. In: PCR Application: Protocols for Functional Genomics. M. A. Innis, D. H. Gelfand, and J. J. Sninsky, eds. Academic Press, San Diego.

22. Zhao, Z. J., He, Y. K., and Shui, Q. J. 2001. Progress of study on potato viruses in Yunnan province, China. J. Sinopotato 15:93-95. (In Chinese)

23. Zhou, X. P., Chen, J. S., Li, D. B., and Li, W. M. 1994. A method for high yield purification of Potyviruses. Microbiology 21(3):184-186. (In Chinese) 